\title{
Naming times for the Snodgrass and Vanderwart pictures in Spanish
}

\author{
FERNANDO CUETOS \\ University of Oviedo, Oviedo, Spain \\ ANDREW W. ELLIS \\ University of York, York, England \\ and \\ BERNARDO ALVAREZ \\ University of Oviedo, Oviedo, Spain
}

\begin{abstract}
We present new Spanish norms for object familiarity and rated age of acquisition for 140 pictures taken from Snodgrass and Vanderwart (1980), together with data on visual complexity, image agreement, name agreement, word length (in syllables and phonemes), and five measures of word frequency. The pictures were presented to a group of 64 Spanish subjects, and oral naming latencies were recorded. In a multiple regression analysis, age of acquisition, object familiarity, name agreement, word frequency, and word length made significant independent contributions to predicting naming latency.
\end{abstract}

In recent years, numerous papers have been published analyzing the properties of objects and their names that influence picture-naming speed. The findings of such studies are important in the development of cognitive models of object recognition and naming. Many of these studies have used a set of 260 black-and-white line drawings of objects published by Snodgrass and Vanderwart (1980) with American norms for visual complexity, object familiarity, image agreement, and name agreement.

One of the factors that has proven consistently to be a powerful predictor of naming speed is age of acquisition, a measure of the age at which children first learn the names of different objects. Many of the studies have relied on adult estimates of age of acquisition (e.g., Carroll \& White, 1973; Gilhooly \& Gilhooly, 1979; Morrison, Ellis, \& Quinlan, 1992), but Morrison, Chappell, and Ellis (1997) derived objective age-of-acquisition norms from children's object-naming data and showed that there was good agreement between objective and rated measures. Ellis and Morrison (1998) found that objective age of acquisition was a strong predictor of adult object-naming speed in their own data and also in data from Barry, Morrison, and Ellis (1997) and Snodgrass and Yuditsky (1996).

The frequency with which words are used and encountered is another factor that exerts a clear influence on naming speed. Although some studies of frequency effects in object naming could be criticized for failing to control for

This research was supported by Grant DGE-96-PB-0545 from the Spanish government. We thank Joan Snodgrass and Frances Connors for helpful comments on an earlier version of this article. Correspondence concerning this article should be addressed to F. Cuetos, Departamento de Psicologia, Universidad de Oviedo, Plaza Feijoo s/n, 33003 Oviedo, Spain (e-mail: fcuetos@correo.uniovi.es). differences in age of acquisition (Ellis \& Morrison, 1998), an effect of frequency continues to be found when age of acquisition is controlled (Barry et al., 1997; Ellis \& Morrison, 1998; Snodgrass \& Yuditsky, 1996). Another factor to emerge with reasonable consistency as a predictor of naming speed is name agreement, measured as the proportion of speakers who assign the target name to a given object. If an object has more than one plausible, alternative name (e.g., gun/pistol/revolver), the retrieval of any one of those names appears to be slowed, possibly because the target name must compete with the alternatives for selection (Vitkovitch \& Tyrrell, 1995).

All of the above-mentioned studies have involved naming in English. Work in other languages on the factors affecting object-naming speed is limited to a small number of studies in languages such as Dutch (e.g., Jescheniak \& Levelt, 1994) and French (e.g., Bachoud-Lévi, Dupoux, Cohen, \& Mehler, 1998). If models of object recognition and naming are to have universal application, it is important that comparative data be obtained from a wider range of languages. The present paper reports a study in which 64 Spanish participants named 140 pictures taken from the Snodgrass and Vanderwart (1980) set. All the objects had single-word names in Spanish. New norms were obtained for age of acquisition in Spanish for use in the analysis. New norms were also obtained for object familiarity, because of the possibility of crosscultural differences in the familiarity of different objects and because, although Sanfeliu and Fernandez (1996) have published familiarity ratings, some common, everyday objects have surprisingly low familiarity ratings in those norms (e.g., glass, 2.35; chair, 2.10; scissors, 1.43; on a 5-point scale from $1=$ unfamiliar to $5=$ highly $\mathrm{fa}$ miliar), whereas less frequently encountered objects 
have much higher ratings (e.g., rhinoceros, 4.73; tiger, 3.24; snake, 3.82).

Adult word frequencies were taken from the frequency dictionary of Alameda and Cuetos (1995). Measures of the frequency with which children use different object names were also taken from data published by the Spanish Ministry of Education (MEC, 1989) and the Institute of Education (ICE, 1977). Finally, measures of visual complexity, image agreement, and name agreement were taken from Sanfeliu and Fernandez (1996).

\section{METHOD}

\section{Stimuli}

The stimuli were 140 black-and-white line drawings of objects taken from the set of 260 published by Snodgrass and Vanderwart (1980). The selected objects all had single-word names in Spanish, with name agreements of over $84 \%$ (Sanfeliu \& Fernandez, 1996) and with ratings for name agreement, visual complexity, and image agreement being available from Sanfeliu and Fernandez. (Name agreement refers to the percentage of speakers who assign the target name to a given picture, visual complexity is a rated measure of the complexity of the line drawing, and image agreement is a measure of the extent to which the drawing matches the visual image of an object that a person forms on being given the object name.)

Ratings of object familiarity were collected by following the Barry et al. (1997) procedure. Raters were given eight booklets. The first booklet contained the written instructions, which specified that they were to judge the familiarity of each object they would see on a 5-point scale from 1 (very unfamiliar) to 5 (highly familiar). Familiarity was defined as "the degree to which you come in contact with, or think about, the thing depicted." The remaining seven booklets each contained 20 Snodgrass and Vanderwart pictures to be rated. The subjects worked through the booklets in a random order. The raters were 93 first-year psychology students from the University of Oviedo.

The age-of-acquisition ratings were obtained from a sample of 50 students from the University of Oviedo, who were asked to give an estimate of the age at which they believed they had learned each word. The scale on which they had to indicate the acquisition age ranged from 1 to 11 , where $1=$ before 2 vears old, $2=$ two years old, $3=$ three years old, and so on, up to $11=$ eleven years old or older.

Adult word frequencies (fAC) were taken from Alameda and Cuetos's (1995) dictionary of word frequencies, which is based on a corpus of written texts comprising 2 million words. Three further frequency measures were obtained. These are based on studies carried out with Spanish children and published by the Spanish Institute of Education (ICE, 1977) and the Ministry of Education (MEC, 1989). ICE is a written production frequency measure compiled from 3,150 children ranging in age from 8 to 17 years, with 630 children in each of the age groups $8-9,10-11,12-14,15-16$, and 17 years of age. The children were simply instructed to write down all the words they could think of in the space of $5 \mathrm{~min}$ ( 10 for the youngest), not just object names. A total of 9,782 different words were collected.

The MEC (1989) written production frequency measures were developed by the Spanish Ministry of Education, with 8,714 pupils, 6-14 years of age, drawn from every region of Spain. A spontaneous frequency measure (MECsp) followed a procedure similar to that of the ICE frequency: The children had to write down all the words they could think of in the space of $10 \mathrm{~min}$ (for the younger ones) or 5 min (for the older children). The suggested frequency measure (MECsu) used a similar procedure, except that a theme was given and the children were asked to give words related to the theme. Sixty different themes were used. A total of 18,881 different words were collected, using the two procedures. The total frequency measure (MECto) is simply the sum of the two previous ones.

Other variables were the numbers of syllables and phonemes in the spoken Spanish object name.

\section{Subjects and Procedure}

The subjects were 64 undergraduate students of psychology at the University of Oviedo. All were monolingual Spanish speakers, and all participated voluntarily in the experiment. None had participated in the rating exercises.

The experiment was controlled by using the ERTS experimental program (Beringer, 1995). The pictures were presented in the center of a computer screen. The subjects remained seated in front of the screen, with a microphone, held in place by headphones, in front of their mouths that was connected to a voice key. When the picture appeared, the computer chronometer was started, and when the subject gave a response, the chronometer was stopped, and the computer automatically recorded the time elapsed. The picture disappeared from the screen as soon as there was a response, and in its place, a cross appeared in the center of the screen, serving as a fixation point and staying in for $2,000 \mathrm{msec}$. After this time, the fixation point disappeared, and a new picture appeared. The maximum time a picture stayed on the screen was $4,000 \mathrm{msec}$. If, after this time, the subject had given no reply, the picture was replaced by the fixation point, and an error was recorded. Before the start of the experiment, the voice key was adjusted to suit each subject's sensitivity, and six trial items were presented. The instructions were given, basically consisting of an explanation of the experiment and a warning not to move their heads too much, not to cough or breathe loudly, and not to say anything other than the picture names. After the instructions had been given, the first set of stimuli, consisting of 6 practice trials and 70 experimental trials, was presented. After this, there was a short rest; then, the second set was presented, again consisting of 6 practice and 70 experimental pictures. The experiment stimuli were randomized for each subject. Simultaneously with the start of the experiment, a recorder was set running for the later analysis of incorrect responses given by each subject.

\section{RESULTS}

Before calculating the means of the reaction times (RTs), we eliminated those items for which the subjects had given an incorrect response or had triggered the voice key by coughing or moving their heads. There were only $3.28 \%$ incorrect responses and $3.53 \%$ voice key failures.

Following the procedure adopted by Snodgrass and Yuditsky (1996), scores lying more than two standard deviations from the mean were removed, in order to eliminate the influence of outliers. This resulted in the removal of $4.14 \%$ of responses. The mean of the naming times was then calculated for each item. The mean naming speeds for each item are shown in the Appendix, along with the percentage of errors made to each item in the present study, plus the values for each item on the different predictor variables.

The global mean naming latency for the 140 items was $829 \mathrm{msec}$, somewhat slower than the RTs obtained by Barry et al. (1997) with Welsh subjects ( $748 \mathrm{msec}$ ), by Ellis and Morrison (1998) with English subjects ( $794 \mathrm{msec}$ ), and by Snodgrass and Yuditsky (1996) with American subjects (791 msec).

The correlations of each predictor variable with naming RT and the significant correlations between the 12 pre- 
dictor variables are shown in Table 1 . The frequency measures were all transformed, using the formula $\log (1+x)$ to reduce skew.

As in many of the studies mentioned in the introduction, the predictor variable that has the highest simple correlation with naming speed is age of acquisition. Naming time also correlates significantly with object familiarity, name agreement, word length, and each of the frequency measures. There are also, however, significant correlations between some of the predictor variables, meaning that the correlations with naming speed must be interpreted with caution. For example, familiarity correlates with age of acquisition (the more familiar pictures have names that are acquired at an early age) and with frequency (the more familiar pictures have more commonly occurring names), whereas word length correlates with age of acquisition (later acquired words tend to be longer) and word frequency (less frequent words tend to be shorter).

\section{Stepwise Multiple Regression}

A stepwise multiple regression was carried out on the naming RTs, using all 12 predictor variables. Age of acquisition was the first variable to be entered $(\beta=.52$, $t=7.10, p<.0001)$, followed by Alameda and Cuetos's (1995) word frequency $(\beta=-.27, t=-3.53, p<.001)$, percentage of name agreement $(\beta=-.16, t=-2.26$, $p<.05)$, object familiarity $(\beta=-.20, t=-2.23, p<$ $.05)$, number of syllables $(\beta=.15, t=2.14, p<.05)$, and image agreement $(\beta=-.14, t=-2.00, p<.05)$. Multiple $R$ for these six factors was .65 , which was highly significant $(F=15.68, p<.001)$. None of the remaining factors were significant sources of variance.

\section{Simultaneous Multiple Regressions}

Stepwise regressions can be problematic when the predictor variables are themselves intercorrelated (Morris, 1981). Here, for example, five different frequency measures were entered into the stepwise regression analysis, one of which (MECto) is the simple sum of two of the others (MECsu and MECsp). To confirm and strengthen the findings of the stepwise analysis, a set of simultaneous multiple regression analyses were also carried out. These analyses all had age of acquisition, visual complexity, object familiarity, image agreement, and percentage of name agreement as predictor variables, plus one of the five frequency measures (fAC, ICE, MECsp, MECsu, or MEC to) and one of the two length measures (syllables or phonemes). As before, the frequency measures were transformed using the formula $\log (1+x)$.

Table 2 shows the results of the analysis with Alameda and Cuetos's (1995) fAC as the frequency measure and number of syllables as the length measure. The overall regression equation was significant $[F(7,131)=13.38$, $p<.001, R=.646]$. Taken together, the predictor variables accounted for $42 \%$ of the variance. The results are very similar to those of the stepwise regression analysis, with age of acquisition, word frequency, name agreement, object familiarity, number of syllables, and image agreement all making independent contributions toward predicting naming speed. As before, the effect of visual complexity was not significant.

Age of acquisition, name agreement, and object familiarity were significant in all the other simultaneous regressions with number of syllables or number of phonemes as the length measures. With number of phonemes, Alameda and Cuetos's (1995) fAC was again significant. None of the other frequency measures (ICE, MECsp, MECsu, or MECto) made a significant independent contribution, whether combined with number of syllables or number of phonemes as the length measure.

\section{DISCUSSION}

The variable that showed the highest raw correlation with naming RT was age of acquisition. It also proved to be significant in all of the regression analyses. This is very much in line with the findings of studies of naming in English, where age of acquisition is the one factor that has emerged as a significant predictor in every study that

Table 1

Correlation Matrix Among All the Independent Variables and Naming Reaction Time

\begin{tabular}{|c|c|c|c|c|c|c|c|c|c|c|c|c|c|}
\hline Variable & (1) & (2) & (3) & (4) & $(5)$ & (6) & (7) & (8) & (9) & $(10)$ & $(11)$ & $(12)$ & (13) \\
\hline 1. Naming RT & 1.000 & & & & & & & & & & & & \\
\hline 2. AoA & $.519 *$ & 1.000 & & & & & & & & & & & \\
\hline 3. Visual complexity & - & - & 1.000 & & & & & & & & & & \\
\hline 4. Familiarity & $-.474^{*}$ & $-.585^{*}$ & $-.353^{*}$ & 1.000 & & & & & & & & & \\
\hline 5. Image agreement & - & - & - & $一$ & 1.000 & & & & & & & & \\
\hline 6. No. phonemes & $.229^{*}$ & $.231 \dagger$ & - & - & - & 1.000 & & & & & & & \\
\hline 7. No. syllables & $.292^{*}$ & $.212+$ & - & $-.202 \ddagger$ & - & $.863^{*}$ & 1.000 & & & & & & \\
\hline 8. $\%$ Name Agreement & $-.253^{*}$ & $-.190+$ & - & - & $.259^{*}$ & - & - & 1.000 & & & & & \\
\hline 9. $\log (1+f A C)$ & $-.427^{*}$ & $-.384^{*}$ & $-.222 \dagger$ & $.486^{*}$ & $-.219 \dagger$ & $-.297^{*}$ & $-.303^{*}$ & - & 1.000 & & & & \\
\hline 10. $\log (1+\mathrm{ICE})$ & $-.462^{*}$ & $-.612^{*}$ & - & $.622 *$ & $-.194_{+}^{+}$ & $-.213+$ & $-.264 \dagger$ & - & $.592 *$ & 1.000 & & & \\
\hline 11. $\log (1+$ MECsp $)$ & $-.373^{*}$ & $-.492^{*}$ & - & $.429^{*}$ & - & - & - & - & $.670^{*}$ & 1.000 & & & \\
\hline 12. $\log (1+\mathrm{MECsu})$ & $-.397^{*}$ & $-.548^{*}$ & - & $.519 *$ & - & - & - & - & $.442 *$ & $.713^{*}$ & $.888^{*}$ & 1.000 & \\
\hline 13. $\log (1 \ddagger$ MECto $)$ & $-.384^{*}$ & $-.514^{*}$ & - & $.459^{*}$ & - & - & - & - & $.418^{*}$ & $.692^{*}$ & $.993^{*}$ & $.936^{*}$ & 1.000 \\
\hline
\end{tabular}

Note-AoA, age-of-acquisition rating; fAC, adult word frequency; ICE, frequency for children from Institute of Education; MECsp, Ministry of Education spontaneous frequency measure; MECsu, Ministry of Education suggested frequency measure; MECto, Ministry of Education total frequency measure. ${ }^{*} p<.001 .{ }^{\dagger} p<.01 . \quad{ }^{\ddagger} p<.05$. A dash indicates that the correlation was not significant. 
Table 2

Simultaneous Multiple Regression Analysis on the Picture Naming Reaction Times

\begin{tabular}{lrrcrr}
\hline \multicolumn{1}{c}{ Variable } & Mean & \multicolumn{1}{c}{$S D$} & $\beta$ Coefficient & \multicolumn{1}{c}{$S E$} & \multicolumn{1}{c}{$t$ Value } \\
\hline Visual complexity & 2.56 & .88 & -4.31 & 9.94 & -0.47 \\
Object familiarity & 3.24 & 1.07 & -22.60 & 9.47 & $-2.38 \dagger$ \\
Image agreement & 3.75 & .58 & -27.93 & 133.68 & $-2.04 \dagger$ \\
\% name agreement & 96.16 & 4.08 & -3.98 & 1.89 & $-2.11 \dagger$ \\
AoA & 4.21 & .71 & 39.16 & 13.23 & $2.96^{*}$ \\
Log ( I fAC) & 1.55 & .62 & -37.46 & 15.15 & $-2.47^{*}$ \\
No. of syllables & 2.51 & .73 & 24.05 & 10.48 & $2.30^{*}$ \\
\hline
\end{tabular}

Note-AoA, age-of-acquisition rating; $\mathrm{fAC}$, adult word frequency. ${ }^{*} p<.01 . \quad{ }^{\dagger} p<.05$.

has included it (see Ellis \& Morrison, 1998). The present study is the first to extend that observation to object naming in other languages.

Some previous studies of naming in English have failed to observe an effect of word frequency on naming speed, once age of acquisition is controlled statistically (e.g., Carroll \& White, 1973; Gilhooly \& Gilhooly, 1979; Morrison et al., 1992), but more recent studies involving larger numbers of items have typically found an influence of frequency over and above the effect of age of acquisition (Barry et al., 1997; Ellis \& Morrison, 1998; Snodgrass \& Yuditsky, 1996). In the present study, the frequency measure based on adult language samples (fAC) made a significant independent contribution to predicting naming speed in the stepwise multiple regression and in both of the simultaneous regression analyses in which it was included. None of the frequency measures based on child language samples made a significant independent contribution to predicting naming speed. Thus, it may be that, once age of acquisition is accounted for, the most relevant measure of word frequency is the frequency with which adults encounter or use different words in daily life.

Object familiarity, image agreement, and name agreement were the other factors to emerge consistently as significant determinants of naming speed. Object familiarity was significant in certain of the analyses reported by Ellis and Morrison (1998). It might be thought of as the perceptual equivalent of word frequency: The more often an object is encountered (i.e., the more familiar it is), the more easily it is recognized for what it is. Two recent studies of patients with semantic dementia have reported effects of familiarity on object naming and have argued that familiarity influences the ability of these patients either to recognize the objects as familiar or to access their semantic representations (Hirsh \& Funnell, 1995; Ralph, Graham, Ellis, \& Hodges, 1998). Image agreement is the extent to which a picture matches the mental image of an object and might be thought of as a measure of the match or mismatch between the picture and a stored canonical representation of the object's appearance. The closer the image is to the representation, the more quickly it can be recognized.

Effects of name agreement have been reported in a number of previous studies (e.g., Lachman, Shaffer, \& Hennrikus, 1974; Snodgrass \& Yuditsky, 1996; Vitko- vitch \& Tyrrell, 1995). The usual assumption is that, if an object can be given more than one plausible name, naming is slowed by the need to select between them. Finally, word length has tended not to be a significant predictor in studies of English naming, but was so here, when measured in terms of the number of syllables. It may be that this relates to the fact that Spanish is a syllabletimed language, whereas English is stress-timed, but it may also be that Spanish object names cover a wider range of syllable lengths in a more even manner, making an effect of length easier to detect.

Picture naming may be thought of as involving a series of processing stages, one of which involves recognizing the image as a representation of a familiar object. We have suggested that effects of familiarity and image agreement operate at this stage. A subsequent stage involves accessing the spoken name. Contemporary models of lexical processing suggest that the more often a word is activated, the stronger become the connections between it and other representations, including the semantic representations used to activate the word (e.g., Jescheniak \& Levelt, 1994). We would suggest that the fAC effect picks up on those differences in connection strengths.

Brown and Watson (1987) proposed that early-acquired words may have more unitary, localized phonological representations, whereas the representations of lateracquired words may be more distributed. They suggested that the extra processing time incurred in assembling the fragmented representation of a late-acquired word would account for the additional time required for object naming or reading aloud (cf. Morrison \& Ellis, 1995). Whatever the merits of this particular proposal, the present data are certainly compatible with the hypothesis that age of acquisition affects the speed of accessing or retrieving phonological word forms. The effect of number of syllables obtained here, if reliable (cf. Bachoud-Lévi et al., 1998), might indicate that longer words take longer to assemble or that more time is required to initiate their articulation.

Perhaps the most encouraging thing for those engaged in the creation of models of lexical processing that are intended to be universal in their application is the fact that the findings of the present study of object naming in the Spanish language are in such close agreement with the findings of the many previous studies involving speakers of English.

\section{REFERENCES}

Alameda, J. R., \& Cuetos, F. (1995). Diccionario de frecuencias de las unidades linguísticas del castellano. Oviedo: Servicio de Publicaciones de la Universidad de Oviedo.

Bachoud-Lévi, A. C., Dupoux, E., Cohen, L., \& Mehler, J. (1998). Where is the length effect? A cross-linguistic study of speech production. Journal of Memory \& Language, 39, 331-346.

Barry, C., Morrison, C. M., \& Ellis, A. W. (1997). Naming the Snodgrass and Vanderwart pictures: Effects of age of acquisition, frequency and name agreement. Quarterly Journal of Experimental Psychology, 50A, 560-585.

BerINGER, J. (1995). Experimental run time svstem. Frankfurt: BeriSoft. 
Brown, G. D. A., \& WATsON, F. L. (1987). First in, first out: Word learning age and spoken word frequency as predictors of word familiarity and word naming latency. Memory \& Cognition, 15, 208-216.

Carroll, J. B., \& WhITE, M. N. (1973). Word frequency and age-ofacquisition as determiners of picture-naming latency. Quarterly Journal of Experimental Psychology, 25, 85-95.

ElLIS, A. W., \& Morrison, C. M. (1998). Real age of acquisition effects in lexical retrieval. Journal of Experimental Psychology: Learning, Memory, \& Cognition, 24, 515-523.

Gilhooly, K. J., \& GilhoOLY, M. L. (1979). Age-of-acquisition effects in lexical and episodic memory tasks. Memory \& Cognition, 7, 214-223.

Hirsh, K. W., \& Funnell, E. (1995). Those old, familiar things: Age of acquisition, familiarity and lexical access in progressive aphasia. Journal of Neurolinguistics, 9, 23-32.

ICE (1977). Vocabulario básico del español y sus aplicaciones a la enseñanza. Oviedo: Instituto de Ciencias de la Educación.

JescheniaK, J. D., \& Levelt, W. J. M. (1994). Word frequency effects in speech production: Retrieval of syntactic information and of phonological form. Journal of Experimental Psychology: Learning, Memory, \& Cognition, 20, 824-843.

Lachman, R., Shaffer, J. P., \& Hennrikus, D. (1974). Language and cognition: Effects of stimulus codability, name-word frequency, and age of acquisition on lexical reaction time. Journal of Verbal Learning \& Verbal Behavior, 13, 613-625.

MEC (1989). Vocabulario básico en la E.G.B. Madrid: Ministerio de Educación y Ciencia and Editorial Espasa Calpe.

MORRIS, P. E. (1981). Age of acquisition, imagery, recall, and the limitations of multiple-regression analysis. Memory \& Cognition, 9, 277-282.
Morrison, C. M., Chappell, T. D., \& Ellis, A. W. (1997). Age of acquisition norms for a large set of object names and their relation to adult estimates and other variables. Quarterly Journal of Experimental Psychology, 50A, 528-559.

Morrison, C. M., \& Ellis, A. W. (1995). The roles of word frequency and age of acquisition in word naming and lexical decision. Journal of Experimental Psychology: Learning, Memory, \& Cognition, 21, 116-133.

Morrison, C. M., Ellis, A. W., \& Quinlan, P. T. (1992). Age of acquisition, not word frequency, affects object naming, not object recognition. Memory \& Cognition, 20, 705-714.

RalPh, M. A. L., Graham, K. S., Ellis, A. W., \& Hodges, J. R. (1998). Naming in semantic dementia-what matters? Neuropsychologia, 36, 775-784.

Sanfeliu, M. C., \& Fernandez, A. (1996). A set of 254 SnodgrassVanderwart pictures standardized for Spanish: Norms for name agreement, image agreement, familiarity, and visual complexity. Behavior Research Methods, Instruments, \& Computers, 28, 537-555.

SnOdgrass, J. G., \& VANDERWART, M. (1980). A standardized set of 260 pictures: Norms for name agreement, image agreement, familiarity, and visual complexity. Journal of Experimental Psychology: $\mathrm{Hu}$ man Learning \& Memory, 6, 174-215.

SNODGRASS, J. G., \& YudiTSKY, T. (1996). Naming times for the Snodgrass and Vanderwart pictures. Behavior Research Methods, Instruments, \& Computers, 28, 516-536.

VitKoYitCH, M., \& TYRRELL, L. (1995). Sources of disagreement in object naming. Quarterly Journal of Experimental Psychology, 48A, 822-848. 


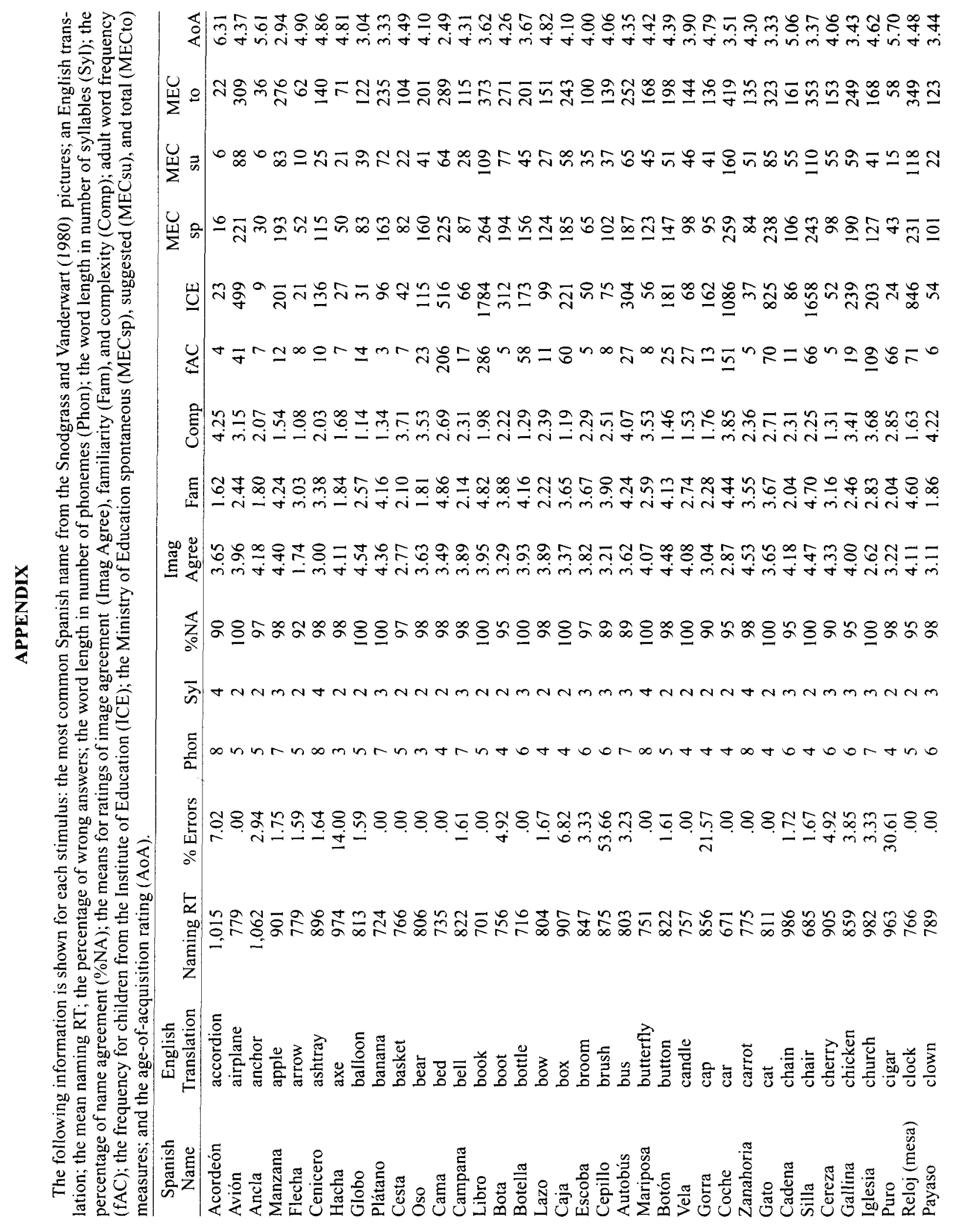




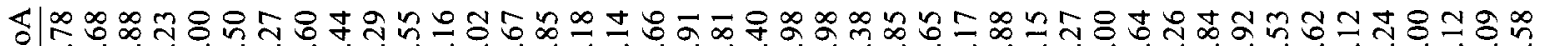

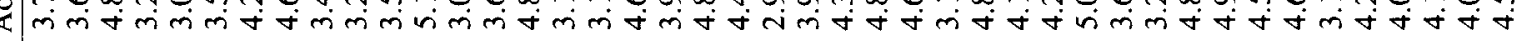
崔

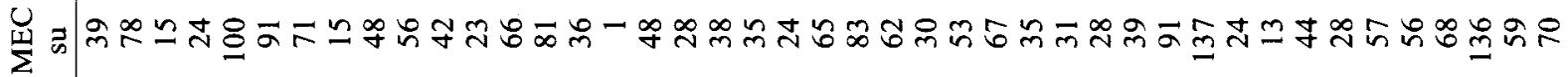

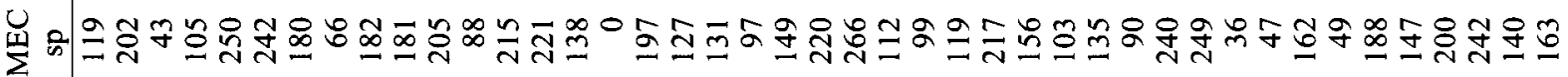

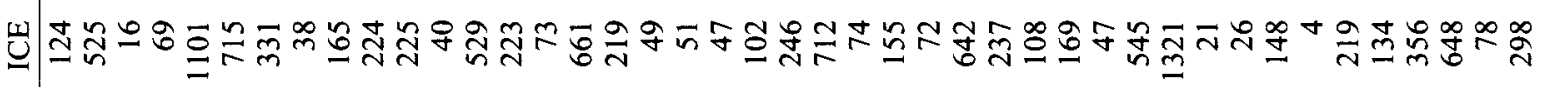

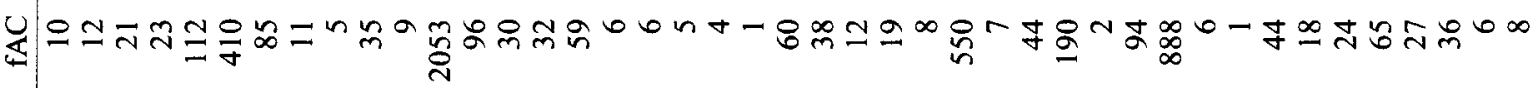

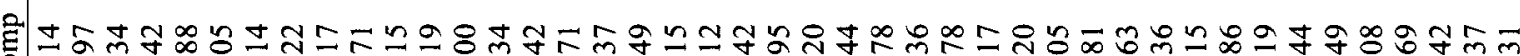

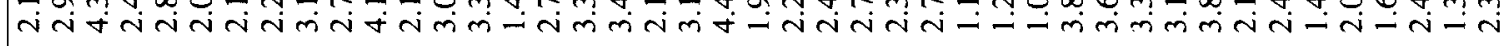

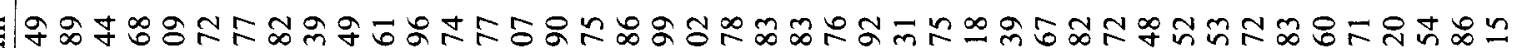

扗

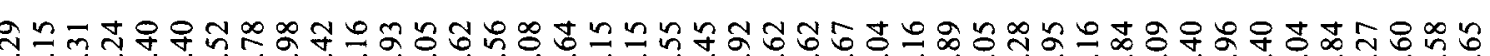

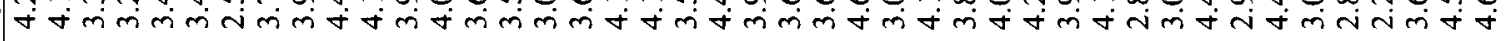

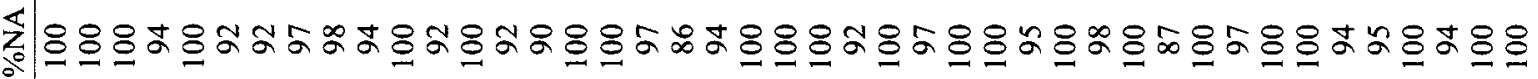

ह

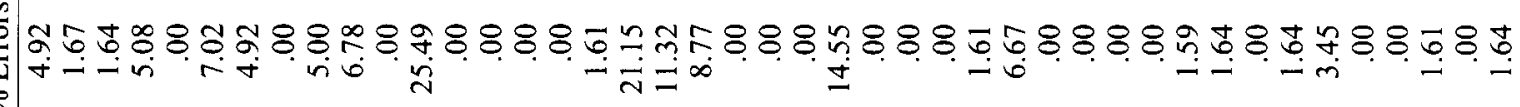
$\circ$

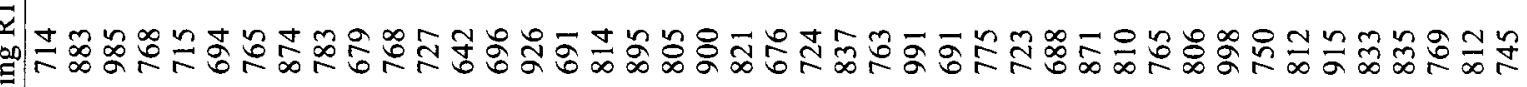

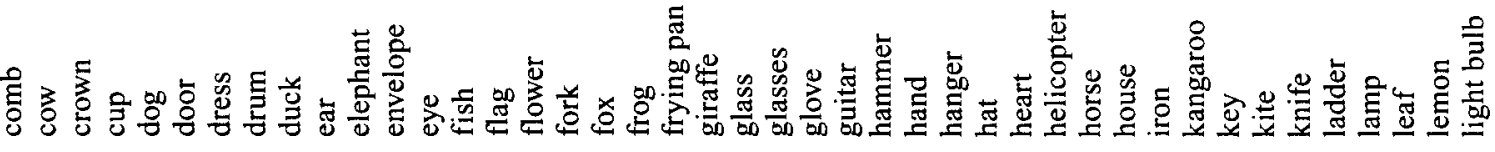




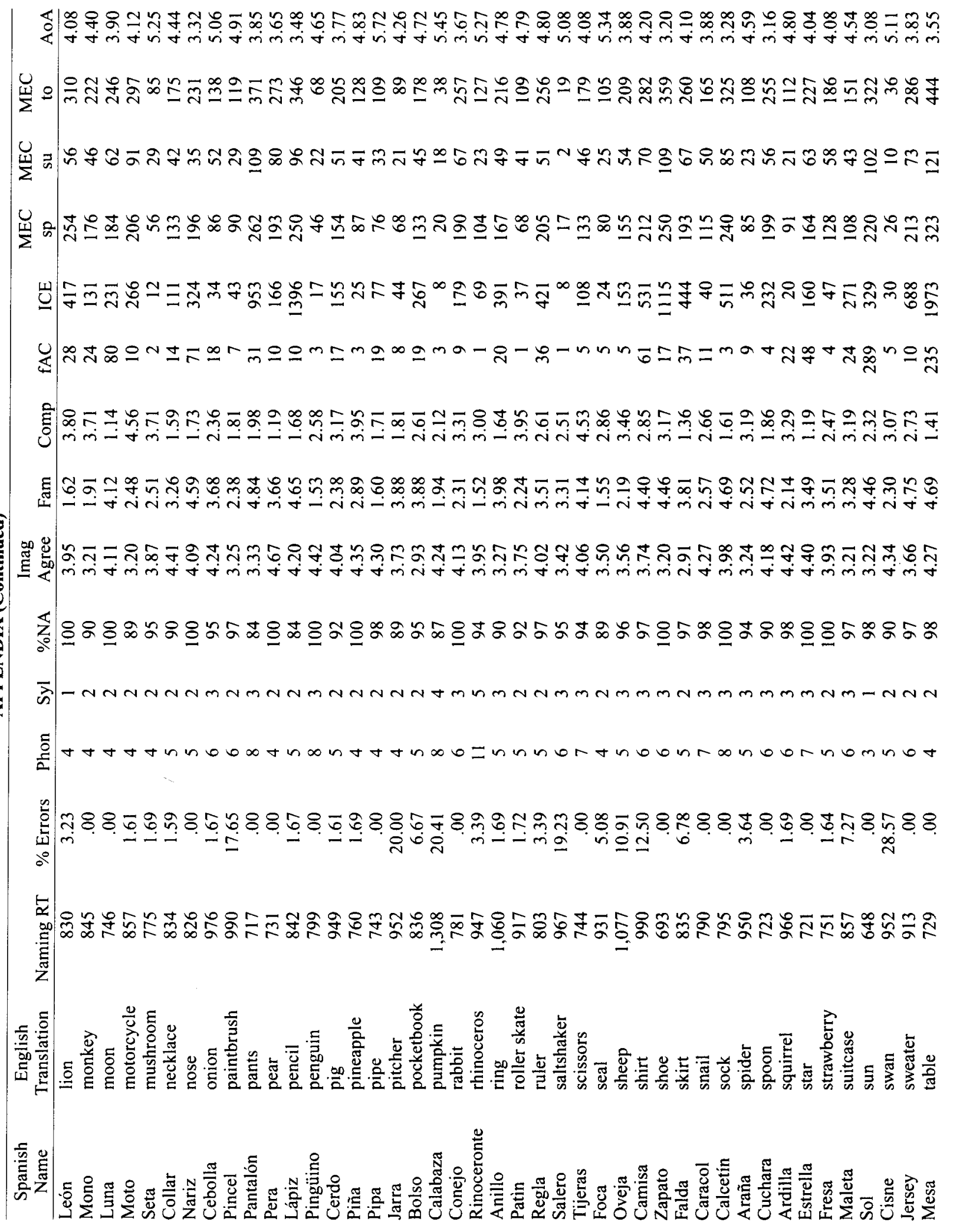




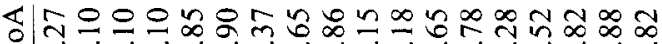

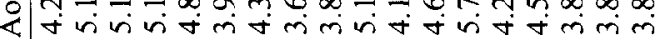
岂

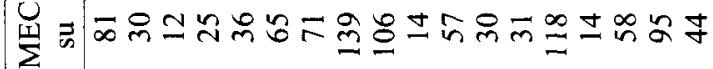
芒 क 峲 यूล

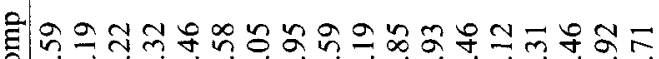

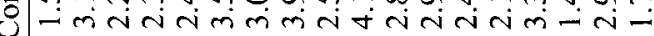

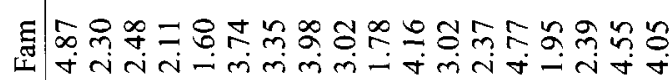

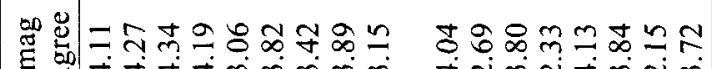

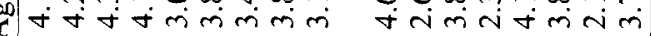

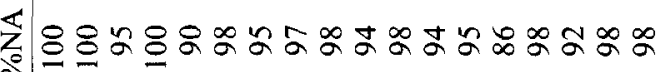
TmNmam- NNmmNmNtNmn

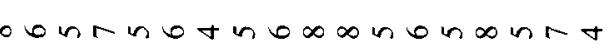

8. $\therefore$

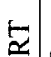

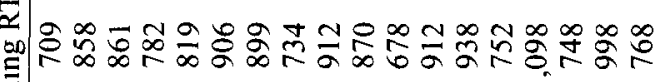
Zू

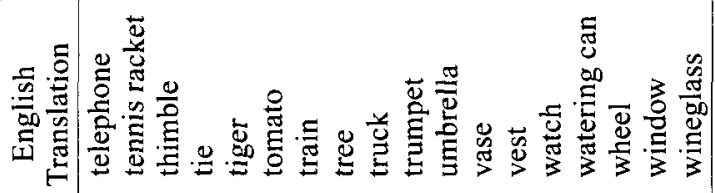

